\title{
Factors Associated With Smoking Status among HIV-Positive Patients in Routine Clinical Care
}

Cosmas M Zyambo ${ }^{1,2,3 *}$, James H Willig ${ }^{2}$, Karen L Cropsey ${ }^{5}$, April P Carson ${ }^{1}$, Craig Wilson ${ }^{1}$, Ashutosh R Tamhane ${ }^{2,4}$, Andrew O Westfall ${ }^{4}$ and Greer A Burkholder ${ }^{2}$

${ }^{1}$ Department of Epidemiology, School of Public Health, University of Alabama at Birmingham, USA

${ }^{2}$ Division of Infectious Diseases, School of Medicine, University of Alabama at Birmingham, USA

${ }^{3}$ Department of Public Health, School of Medicine, University of Zambia, Zambia

${ }^{4}$ Department of Biostatistics, School of Public Health, University of Alabama at Birmingham, USA

${ }^{5}$ Department of Psychiatry, School of Medicine, University of Alabama at Birmingham, USA

\begin{abstract}
Background: Treatment-related reductions in morbidity and mortality among human immunodeficiency virus (HIV)-positive patients have been attenuated by cigarette smoking, which increases risk of cardiovascular, respiratory, and neoplastic diseases. This study investigated factors associated with smoking status among HIV-positive patients.

Methods: This cross-sectional study included 2,464 HIV-positive patients attending the HIV Clinic at the University of Alabama at Birmingham between April 2008 and December 2013. Smoking status (current, former, never), psychosocial factors, and clinical characteristics were assessed. Multinomial logistic regression was used to obtain unadjusted and adjusted odds ratios (OR) and $95 \%$ confidence intervals $(\mathrm{Cl})$ for the association of the various factors with smoking status.
\end{abstract}

Results: Among HIV-positive patients (mean age 45 years, 75\% male, 55\% African-American), the majority reported a history of smoking (39\% current and $22 \%$ former smokers). In adjusted models, patient characteristics associated with increased odds of current smoking were male gender (OR for heterosexual men, 1.8 [95\% Cl: 1.3-2.6]; for men who have sex with men, 1.5 [1.1-1.9]), history of respiratory diseases (1.5 [1.2-1.9]), unsuppressed HIV viral load (>50 copies $/ \mathrm{mL})(1.5$ [1.1-1.9]), depression (1.6 [1.3-2.0]), anxiety (1.6 [1.2-2.1]), and prior and current substance abuse (4.7 [3.6-6.1] and 8.3 [5.3-13.3] respectively). Male gender, anxiety, and substance abuse were also associated with being a former smoker.

Conclusions: Smoking was common among HIV-positive patients, with several psychosocial factors associated with current and former smoking. This suggests smoking cessation programs in HIV clinic settings may achieve greater impact by integrating interventions that also address illicit substance abuse and mental health.

Keywords: Smoking; HIV; Risk factors

\section{Background}

While the life expectancy of persons with human immunodeficiency virus (HIV) has increased with effective antiretroviral therapy (ART) [1-3], smoking remains an important health risk. Currently, smoking is the leading preventable cause of morbidity and mortality in the United States (US) [4], and it is a risk factor for many chronic diseases including cardiovascular disease (CVD), chronic obstructive pulmonary disease (COPD), and numerous types of cancer [5-7]. In the US, tobacco-related diseases account for approximately 480,000 deaths and are directly responsible for national healthcare expenditures and productivity loses of approximately $\$ 289$ billion every year [8]. While an estimated $17.8 \%$ (42.1 million) of US adults smoke [9], the prevalence of smoking among HIV-positive individuals is $2-3$ times higher [10-13].

The higher prevalence of smoking among HIV-positive patients has significant public health implications including the higher mortality rates among smokers [14-16]. In a study of US veterans, Crothers et al. showed that the mortality rates per 100 personyears were 1.76 for HIV-negative patients who had never smoked, 2.45 for HIV-positive patients who had never smoked, and 5.48 for HIV-positive patients who were current smokers [15]. In addition, smoking is a contributor to the higher rates of cardiovascular events, COPD, and lung cancer observed in HIV-positive patients compared to uninfected persons [17-19]. These findings raise the concern that although advances in HIV treatment have resulted in morbidity and mortality reductions, the gains of ART may be attenuated by high rates of cigarette smoking.

Research on factors associated with current smoking among HIV-positive patients may assist health care providers to implement targeted smoking cessation programs addressing smoking and these other factors. Most previous studies investigating factors associated with smoking among HIV-positive patients have used small sample sizes or were clinical trials [12,20-22]. Therefore, the purpose of the current study was to investigate socio-demographics, psychosocial factors, and clinical characteristics associated with smoking status among a large population of HIV-positive patients in a routine clinical setting in the southeastern US.

*Corresponding authors: Cosmas M Zyambo, Department of Epidemiology, School of Public Health, University of Alabama at Birmingham, BBRB 220C, 845 19th Street S, Birmingham, Alabama 35294, USA, Tel: 205-587-6893; Fax: 205934-5600; E-mail: cosmas@uab.edu

Received May 05, 2014; Accepted June 30, 2015; Published July 09, 2015

Citation: Zyambo CM, Willig JH, Cropsey KL, Carson AP, Wilson C, et al. (2015) Factors Associated With Smoking Status among HIV-Positive Patients in Routine Clinical Care. J AIDS Clin Res 6: 480. doi:10.4172/2155-6113.1000480

Copyright: (c) 2015 Zyambo CM, et al. This is an open-access article distributed under the terms of the Creative Commons Attribution License, which permits unrestricted use, distribution, and reproduction in any medium, provided the original author and source are credited. 


\section{Methods}

\section{Study setting}

This cross-sectional study was conducted using data from the University of Alabama at Birmingham (UAB) 1917 HIV Clinic Cohort protocol, which has prospectively collected detailed socio-demographic, psychosocial, and clinical data on HIV-positive patients receiving primary HIV and subspecialty care at the UAB 1917 HIV/AIDS Clinic (1917 Clinic) since 1992 ( $N>8,000$ patients overall; $>3,000$ active). This study was approved by the UAB Institutional Review Board.

\section{Eligibility criteria}

All HIV-positive patients, aged $\geq 19$ years, who attended the outpatient clinic between April 2008 and December 2013 and who completed a self-administered survey during the index visit were eligible. This survey was not available prior to April 2008. The index visit was the most recent patient visit between April 2008 and December 2013. A total of 2,528 HIV-positive patients met the eligibility criteria. However, 2.5\% (63) were excluded from the analysis because they did not answer any of the tobacco use questions in the survey. Patients of race/ethnicity other than Caucasian or African-American were excluded for low numbers. 2,464 HIV-positive patients were included in the final analysis.

\section{Data sources}

Socio-demographics, diagnoses, medications, and laboratory data were obtained by electronic data query of the 1917 Clinic Cohort database using MS SQL Server 2008. The 1917 Clinic uses a patient-reported outcomes (PRO) software capture system to collect psychosocial information from patients. The system employs standardized and validated questionnaires that are self-administered via computer touchscreens during patient visits. The questionnaires include assessments on smoking, depression (Patient Health Questionnaire-9 [PHQ-9]), anxiety (Patient Health QuestionnaireAnxiety [PHQ-Anxiety]), substance use (Alcohol, Smoking, and Substance Involvement Screening Test [ASSIST]), and ART adherence (Adult AIDS Clinical Trials Group [AACTG] Adherence Instrument) [23].

\section{Variables}

Outcome variable: The outcome of interest was smoking status, which was categorized as never smoker, former smoker, or current smoker as defined by the tobacco use questionnaire. Patients were classified as "current smokers" if they answered "yes" to the question, "Do you currently smoke cigarettes?" Patients who reported having smoked more than 20 cigarettes in their lifetime but who were not current smokers were classified as "former smokers". Those who did not meet the criteria for current or former smokers were classified as "never smokers".

Independent variables: The independent variables collected were: 1) Socio-demographics including age, composite gender/sexual orientation (men who have sex with men [MSM], heterosexual men, and women), and race (Caucasian, African-American). 2) Psychosocial factors including depression (major or other depressive symptoms based on PHQ-9 scoring); anxiety (symptoms of anxiety or panic syndrome based on PHQ-Anxiety scoring), and substance abuse as per the ASSIST (opioids, marijuana, crack/cocaine, amphetamines). 3) Clinical variables including ART adherence (missing $\geq 1$ dose over the previous 1 month using the AACTG Adherence instrument was considered non-adherent), history of cardiovascular diseases (stroke, myocardial infarction, coronary heart disease [CHD], and hypertension), history of respiratory diseases (asthma, COPD, and bacterial pneumonia), history of metabolic diseases (diabetes and dyslipidemia), and laboratory values (closest CD4 count and plasma HIV-1 RNA [viral load; VL]). A history of comorbidity was defined as ever being diagnosed with that comorbidity on or prior to the index visit. Laboratory values from the index visit or prior to the index visit were used.

\section{Statistical analyses}

The variables in the study were evaluated using descriptive statistics including chi-square and analysis of variance (ANOVA) as appropriate. Continuous variables are reported as means with standard deviations (SD) and categorical variables as frequencies with percentages. Multinomial (polytomous) logistic regression was used to examine the factors associated with current and former smoking in unadjusted and adjusted models, using never smokers as the referent. Odds ratios (OR) and $95 \%$ confidence intervals $(\mathrm{CI})$ were obtained from univariate and multivariable models. All the variables were felt to be clinically relevant and included in the adjusted model. Statistical significance was set at the 0.05 level (two-tailed test). Analyses were performed using SAS version 9.3 (SAS Institute, Cary, NC).

\section{Results}

Overall, 39\% of HIV-positive patients were current smokers and $22 \%$ were former smokers (Table 1 ). The mean age ( \pm standard deviation) was $45 \pm 11$ years and the population was predominantly African American (55\%). The majority of the patients were male (75\%), and $59 \%$ were MSM. HIV VL was detectable $(\geq 50$ copies $/ \mathrm{mL}$ ) in $29 \%$ of patients, and $12 \%$ of patients had a CD4 count of $<200$ cells/ $\mu \mathrm{L}$. Cardiovascular diseases $(48 \%)$, metabolic diseases $(41 \%)$, and respiratory diseases (23\%) were common overall. Among patients with history of respiratory diseases, current smoking was more prevalent than among those with history of cardiovascular and metabolic diseases. For psychosocial factors, $49 \%$ of patients with depression, $51 \%$ of patients with anxiety, and $73 \%$ of current substance users were also current smokers.

\section{Factors associated with current and former smoking}

In the univariate analyses, male heterosexual, MSM, ART nonadherence, history of respiratory disease, detectable HIV VL $(>50$ copies $/ \mathrm{mL}$ ), depression, anxiety, and current and prior substance abuse were significantly associated with increased odds of being a current smoker (Table 2). In contrast, African-American race, and history of cardiovascular or metabolic disease were associated with significantly decreased odds of current smoking. Older age, male heterosexual, MSM, history of metabolic disease or cancer, depression, anxiety, and current and prior substance abuse were significantly associated with increased odds of being a former smoker. African-American race was associated with significantly decreased odds of being a former smoker.

In adjusted analyses, factors significantly associated with being a current smoker included male heterosexual (OR, 1.8 [95\% CI: 1.32.6]), MSM (1.5 [1.1-1.9]), history of respiratory disease (1.5 [1.2-1.9]), detectable VL (1.5 [1.1-1.9]), depression (1.6 [1.3-2.0]), anxiety (1.6 [1.2-2.1]), prior substance abuse (4.7 [3.6-6.1]), and current substance abuse (8.3 [5.3-13.3]) (Table 2). African-American race (0.7 [0.6-0.9]) and history of cardiovascular disease (OR, 0.8 [0.6-0.9]) or metabolic diseases (OR, 0.8 [0.6-0.9]), were associated with significantly decreased odds of being a current smoker. Factors which were significantly associated with former smoking included older age (OR per 10 year increase, 1.3 [1.2-1.5]), male heterosexual (2.3 [1.5-3.2]), MSM (1.7 


\begin{tabular}{|c|c|c|c|c|}
\hline & Overall & Never smokers & Former smokers & Current smokers \\
\hline \multirow[t]{2}{*}{ Variables } & $(N=2,464)$ & $(n=970)$ & $(n=538)$ & $(n=956)$ \\
\hline & $\mathrm{n}(\%)^{\mathrm{a}}$ & $\mathrm{n}(\%)^{\mathrm{b}}$ & $\mathrm{n}(\%)^{\mathrm{b}}$ & $n(\%)^{b}$ \\
\hline \multicolumn{5}{|l|}{ Sociodemographic } \\
\hline Age (years), mean (SD) & $45.4(11.4)$ & $44.5(11.8)$ & $48.2(11.3)$ & $44.6(10.7)$ \\
\hline \multicolumn{5}{|l|}{ Gender/sexual orientation } \\
\hline Women & $542(22.0)$ & $267(49.3)$ & $86(15.9)$ & $189(34.8)$ \\
\hline Male heterosexual & $405(16.4)$ & $146(36.0)$ & $101(24.9)$ & $158(39.0)$ \\
\hline MSM & $1447(58.7)$ & $542(37.5)$ & $332(22.9)$ & $573(39.5)$ \\
\hline \multicolumn{5}{|l|}{ Race/ethnicity } \\
\hline Caucasian & $1,090(45.4)$ & $328(30.0)$ & $295(27.1)$ & $467(42.9)$ \\
\hline African American & $1,310(54.6)$ & $612(46.7)$ & $228(17.4)$ & $470(35.9)$ \\
\hline \multicolumn{5}{|l|}{ Clinical } \\
\hline \multicolumn{5}{|l|}{ ART Adherence } \\
\hline Non-adherent & $295(12.0)$ & $103(34.9)$ & $49(16.6)$ & $143(48.5)$ \\
\hline \multicolumn{5}{|l|}{ Comorbidities $^{c}$} \\
\hline Cardiovascular & $1,182(48.0)$ & $499(42.2)$ & $292(24.7)$ & $391(33.1)$ \\
\hline Respiratory & $555(22.5)$ & $198(35.7)$ & $114(20.5)$ & $243(43.8)$ \\
\hline Metabolic & $1,009(40.9)$ & $413(40.9)$ & $267(26.5)$ & $329(32.6)$ \\
\hline Any cancers & $280(11.4)$ & $107(38.2)$ & $80(28.6)$ & $93(33.2)$ \\
\hline \multicolumn{5}{|l|}{ Laboratory parameters $^{d}$} \\
\hline \multicolumn{5}{|l|}{ Viral Load (copies/mL) } \\
\hline Detectable $(\geq 50)$ & $702(28.6)$ & $242(35.5)$ & $131(18.7)$ & $329(46.9)$ \\
\hline \multicolumn{5}{|l|}{ CD4 count (cells $/ \mu \mathrm{L})$} \\
\hline$<200$ & $297(12.1)$ & $120(40.4)$ & $54(18.2)$ & $123(41.4)$ \\
\hline $200-350$ & $367(15.0)$ & $145(39.5)$ & $86(23.4)$ & $136(37.1)$ \\
\hline$>350$ & $1,789(72.9)$ & $701(39.2)$ & $396(22.1)$ & $692(38.7)$ \\
\hline \multicolumn{5}{|l|}{ Psychosocial } \\
\hline Depression & $992(40.8)$ & $299(30.1)$ & $207(20.8)$ & $486(48.9)$ \\
\hline Anxiety & $580(24.0)$ & $154(26.6)$ & $128(22.1)$ & $298(51.4)$ \\
\hline \multicolumn{5}{|l|}{ Substance abuse ${ }^{e}$} \\
\hline Never & $1,512(61.1)$ & $804(53.2)$ & $294(19.4)$ & $414(27.3)$ \\
\hline Prior & $733(29.9)$ & $134(18.3)$ & 212 (28.9) & $387(52.7)$ \\
\hline Current & $210(8.6)$ & 27 (12.9) & $30(14.3)$ & $153(72.9)$ \\
\hline
\end{tabular}

Abbreviations: ART-Antiretroviral Therapy; HIV- Human Immunodeficiency Virus; MSM- Men who have sex with men; SD- Standard Deviation; UAB- University of Alabama, Birmingham

Comorbidities: Cardiovascular (stroke, myocardial infarction, coronary artery disease, hypertension); Respiratory (asthma, chronic obstructive pulmonary disease, bacterial pneumonia); Metabolic (diabetes and dyslipidemia);

Missing data: Gender/sexual orientation, $2.8 \%$; adherence, 0.6\%; Race, 2.6\%; viral load, 0.4\%; depression (PHQ-9), 1.3\%; anxiety (PHQ-A), 1.7\%; substance abuse (ASSIST), $1.7 \%$

All the variables were significant at $p$ value $<0.05$ level except for CD4 count

${ }^{a}$ Column percentages; ${ }^{b}$ row percentages; ${ }^{c}$ Yes to history of comorbidities; ${ }^{d}$ Lab value closest on or prior to index visit; ${ }^{\text {e }}$ Substance abuse includes (opioids, marijuana, crack/cocaine, amphetamines)

[1.2-2.4]), anxiety (1.5 [1.1-2.0]), prior substance abuse (3.2 [2.5-4.3]), and current substance abuse (2.6 [1.4-4.6]), whereas African-American race was associated with significantly decreased odds of former smoking (0.6 [0.5-0.8]).

\section{Discussion}

In this population of HIV-positive patients receiving routine clinical care, $39 \%$ of patients reported being current smokers. This estimate is slightly lower than what has been reported in previous studies among HIV-positive persons (40-59\%) [10-13], yet it remains notably higher than the smoking prevalence found in the general US population (20.6\%) [10] and in Alabama (22\%) [24]. Twenty-two percent of the HIV-positive patients in our study population were former smokers, and compared with current smokers, they were less likely to have depression or be current substance abusers. This suggests that there may be opportunities for combining smoking cessation programs with targeted interventions to address mental health and substance abuse issues among current smokers with HIV who have these comorbidities.

In the context of numerous studies that have demonstrated an association of mental illness with cigarette smoking among both the general population and HIV-infected patients [10, 25-27], it is not surprising that roughly half of our patients with depression and anxiety were current smokers. A potential reason for the high co-occurrence of current smoking with mental illness is that some patients may smoke to cope with psychological distress, including the stress of living with HIV [25,27].

Our study examined overall substance abuse, including crack/ cocaine, marijuana, amphetamine and opioids, and found that substance abuse was strongly associated with current and former smoking status, similar to findings reported in prior studies among both the general population and HIV-infected patients $[10,28,29]$. The association 
Citation: Zyambo CM, Willig JH, Cropsey KL, Carson AP, Wilson C, et al. (2015) Factors Associated With Smoking Status among HIV-Positive Patients in Routine Clinical Care. J AIDS Clin Res 6: 480. doi:10.4172/2155-6113.1000480

Page 4 of 7

Table 2: Multinomial logistic regression model examining the factors associated with current and former smoking among HIV-positive patients receiving care at the UAB 1917 HIVIAIDS clinic April 2008-December $2013(\mathrm{~N}=2,464)$.

\begin{tabular}{|c|c|c|c|c|}
\hline & \multicolumn{4}{|c|}{ Smoking status } \\
\hline & \multicolumn{2}{|c|}{ Former smokers } & \multicolumn{2}{|c|}{ Current Smokers } \\
\hline & Unadjusted & Adjusted & Unadjusted & Adjusted \\
\hline & OR $(95 \% \mathrm{Cls})$ & OR (95\% Cls) & OR $(95 \% \mathrm{Cls})$ & OR $(95 \% \mathrm{Cls})$ \\
\hline \multicolumn{5}{|l|}{ Sociodemographics } \\
\hline Age (per 10 years) ${ }^{a}$ & $1.3(1.2-1.5)$ & $1.3(1.2-1.5)^{\star *}$ & $1.0(0.9-1.1)$ & $1.0(0.9-1.2)$ \\
\hline \multicolumn{5}{|c|}{ Gender/sexual orientation } \\
\hline Women & 1.0 & 1.0 & 1.0 & 1.0 \\
\hline Male heterosexual & $2.1(1.5-3.0)$ & $2.3(1.5-3.2)^{\star *}$ & $1.5(1.1-2.0)$ & $1.8(1.3-2.6)^{* *}$ \\
\hline MSM & $1.9(1.5-2.7)$ & $1.7(1.2-2.4)^{\star}$ & $1.5(1.2-1.9)$ & $1.5(1.1-1.9)^{*}$ \\
\hline \multicolumn{5}{|l|}{ Race/ethnicity } \\
\hline Caucasian & 1.0 & 1.0 & 1.0 & 1.0 \\
\hline African American & $0.4(0.3-0.5)$ & $0.6(0.5-0.8)^{\star *}$ & $0.6(0.5-0.6)$ & $0.7(0.6-0.9)^{*}$ \\
\hline \multicolumn{5}{|l|}{ Clinical } \\
\hline \multicolumn{5}{|l|}{ ART Adherence } \\
\hline Adherent & 1.0 & 1.0 & 1.0 & 1.0 \\
\hline Non-adherent & $0.8(0.5-1.2)$ & $0.9(0.6-1.5)$ & $1.5(1.1-1.9)$ & $1.1(0.7-1.6)$ \\
\hline \multicolumn{5}{|l|}{ Comorbidities $^{\text {b }}$} \\
\hline Cardiovascular & $1.1(0.9-1.3)$ & $0.9(0.8-1.3)$ & $0.7(0.5-0.8)$ & $0.8(0.6-0.9)^{*}$ \\
\hline Respiratory & $1.0(0.8-1.4)$ & $1.0(0.7-1.4)$ & $1.3(1.1-1.6)$ & $1.5(1.2-1.9)^{*}$ \\
\hline Metabolic & $1.3(1.1-1.6)$ & $0.9(0.7-1.2)$ & $0.7(0.6-0.9)$ & $0.8(0.6-0.9)^{*}$ \\
\hline Any cancer & $1.4(1.0-1.9)$ & $0.9(0.6-1.4)$ & $0.8(0.6-1.1)$ & $0.7(0.5-1.1)$ \\
\hline \multicolumn{5}{|l|}{ Laboratory parameters $^{c}$} \\
\hline \multicolumn{5}{|c|}{ Plasma HIV-1 (copies/mL) } \\
\hline Undetectable $(<50)$ & 1.0 & 1.0 & 1.0 & 1.0 \\
\hline Detectable $(\geq 50)$ & $0.9(0.7-1.2)$ & $1.2(0.8-1.6)$ & $1.6(1.3-1.9)$ & $1.5(1.1-1.9)^{*}$ \\
\hline \multicolumn{5}{|l|}{ CD4 count (cells/ $\mu \mathrm{L})$} \\
\hline$<200$ & 1.0 & 1.0 & 1.0 & 1.0 \\
\hline $200-350$ & $1.3(0.8-2.0)$ & $0.9(0.6-1.4)$ & $0.9(0.7-1.2)$ & $0.9(0.6-1.2)$ \\
\hline$>350$ & $1.2(0.8-1.7)$ & $0.7(0.5-1.2)$ & $1.0(0.7-1.3)$ & $0.8(0.5-1.2)$ \\
\hline \multicolumn{5}{|l|}{ Psychosocial } \\
\hline \multicolumn{5}{|l|}{ Depression } \\
\hline Not depressed & 1.0 & 1.0 & 1.0 & 1.0 \\
\hline Depressed & $1.4(1.1-1.7)$ & $1.2(0.9-1.5)$ & $2.3(1.9-2.8)$ & $1.6(1.3-2.0)^{\star *}$ \\
\hline \multicolumn{5}{|l|}{ Anxiety } \\
\hline No anxiety & 1.0 & 1.0 & 1.0 & 1.0 \\
\hline Anxiety & $1.7(1.3-2.2)$ & $1.5(1.1-2.0)^{*}$ & $2.4(1.9-2.9)$ & $1.6(1.2-2.1)^{*}$ \\
\hline \multicolumn{5}{|l|}{ Substance use ${ }^{d}$} \\
\hline Never & 1.0 & 1.0 & 1.0 & 1.0 \\
\hline Prior & $4.3(3.3-5.6)$ & $3.2(2.5-4.3)^{\star *}$ & $5.6(4.5-7.1)$ & $4.7(3.6-6.1)^{* *}$ \\
\hline Current & $3.0(1.8-5.2)$ & $2.6(1.4-4.6)^{*}$ & $11.0(7.2-16.8)$ & $8.3(5.3-13.3)^{\star *}$ \\
\hline
\end{tabular}

Abbreviations: AIDS- Acquired Immunodeficiency Syndrome; ART- Antiretroviral Therapy; Cl- Confidence Interval; HIV- Human Immunodeficiency Virus; MSM- Men who have sex with men; UAB- University of Alabama, Birmingham

All the variables were included in the adjusted model. Boldface indicates statistical significance: ${ }^{*} \mathrm{P}<0.05$ levels, ${ }^{* *} \mathrm{P}<0.001$. Non-smokers were used as the reference group. All the variables were added in the adjusted model

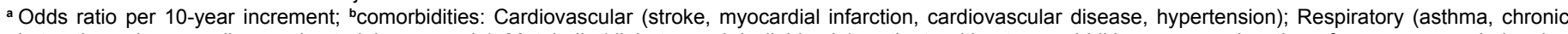
obstructive pulmonary disease, bacterial pneumonia); Metabolic (diabetes and dyslipidemia), patients without comorbidities were used as the reference group; ${ }^{\mathrm{C}}$ Lab value closest on or prior to index visit; ${ }^{\text {d }}$ substance abuse (opioids, marijuana, crack/cocaine, amphetamine)

between current substance abuse and current smoking was especially strong. Similar social, genetic, and personality factors are associated with smoking and substance abuse [30-33]. In addition, there are similarities in the neurophysiology of addiction to nicotine and illicit drugs [34]. Smoking cessation interventions among both the general population and HIV-positive patients have traditionally addressed smoking independent of other comorbidities. However, given the correlations of mental illness and substance abuse with current smoking among HIV-positive patients observed in our study and others, an important approach toward smoking cessation in routine HIV care settings might be to address smoking cessation as part of the care offered for these comorbid conditions, as has been advocated by some for the general population [35]. Such approaches may be of particular importance among HIV-positive patients given that there is higher prevalence of mental illness and substance abuse in this population which likely contribute significantly to higher rates of smoking $[10,27]$. Of note, recent studies suggest readiness to quit among smokers 
with depression and substance abuse does not differ significantly from smokers without these conditions and thus it is reasonable to pursue smoking cessation interventions among these patients [22,35].

After adjusting for socio-demographic, clinical, and psychosocial factors, our analyses showed that patients with detectable HIV VL ( $>50$ copies $/ \mathrm{mL}$ ) were significantly more likely to be current smokers. This finding is similar to results from other studies that demonstrated that current smoking status was associated with failed virological suppression for patients on ART [36,37]. However, this association was not present among former smokers in our study. A potential explanation may be that current smokers are less likely to engage in selfcare behaviors such as ART adherence compared with former or never smokers. In our study, patients who were non-adherent to ART were more likely to be current than former or never smokers, however, in our multinomial logistic regression analyses, no significant association was found between ART adherence and smoking status. The proportion of patients non-adherent to ART in our study was low (12\%), limiting our ability to make broad inferences about this segment of our population.

A history of respiratory diseases (asthma, COPD, and bacterial pneumonia) was significantly associated with increased odds of current smoking in our study. Studies have shown that respiratory diseases, such as COPD, are common among HIV-positive patients, occurring at higher rates than observed in uninfected persons, and may have a more accelerated course $[18,38,39]$. While smoking is a strong contributor to COPD among HIV-infected patients, an excess risk remains compared to uninfected persons even when adjusting for smoking $[39,40]$. Persons with HIV appear to be more susceptible to the damaging effects of smoking $[18,41]$. The pathophysiology is incompletely understood, however hypotheses have been advanced suggesting that tissue inflammatory processes, altered antioxidant-oxidant balance, and increased apoptosis of the lung epithelial and endothelial cells play a role [39]. Smokers with concomitant respiratory co-morbidities should be aggressively targeted in smoking cessation interventions in HIV care settings.

Smoking is a risk factor for cardiovascular diseases in both general and HIV-positive populations [11,14]. In our cohort, patients with a history of cardiovascular diseases (stroke, myocardial infarction, CHD, or hypertension) were significantly less likely to be current smokers. A similar lower odds of current smoking was observed in patients with metabolic diseases. One possible explanation is that patients diagnosed with these disorders may be more motivated to quit smoking or receive more smoking cessation counseling from HIV providers or other physicians $[42,43]$. If this is correct, it suggests increased focus on subpopulations at risk can lead to lower smoking rates in the HIV care setting.

Our study participants were predominantly African-American and male. Studies have demonstrated that African-Americans have about the same prevalence of smoking as Caucasians but seemingly more difficulty with quitting smoking. This may be due to socioeconomic disadvantages such as being less likely to receive smoking cessation counseling and treatment $[44,45]$. However, in our population, African Americans were less likely to be current or former smokers, even when adjusting for gender. This finding was unexpected and bears further study. Our participants were predominantly MSM. Prior studies have shown higher smoking rates among MSM than heterosexual men in the general population as well as among HIV-positive patients [9,46,47]. In contrast, in our study prevalence of current smoking was similar between MSM and heterosexual males.
One of the major strengths of this study is the large sample size. Our study involved HIV-positive patients from a routine clinical care setting. These patients tend to differ from those sampled in clinical trials and often represent a more diverse population due to the absence of enforcement of any enrollment criteria. Most prior studies evaluating patient characteristics related to smoking among HIV-positive patients have had small sample sizes or were clinical trials. An exception is a recent study by Mdodo et al. including a large population of HIVpositive patients participating in the nationally distributed Medical Monitoring Program [10]. Our findings on the association of depression and substance abuse with smoking among HIV-positive patients corroborate the findings of this study. We used patient-reported data in our analyses, which have been shown to be more accurate in many sensitive domains $[48,49]$, but may be biased because of self-reporting. Although self-reporting often underestimates the prevalence of smoking [50], other studies have shown that computer-administered questionnaires have comparable validity with clinical interviews [51]. Finally, our analyses included medical comorbidities, which have been absent from most prior studies.

Our results should also be interpreted with regard to the limitations of our study. Because of the observational design, we only were able to identify the factors associated with smoking status and were unable to address causality. We were unable to assess changes in these factors over time. Despite adjusting for known confounders in the multivariable model, the potential for the residual confounders inherent in observational studies remains and might affect the interpretation of study outcomes. We analyzed data of patients who completed the PROs during the study period and lack information on the patients who did not take part. However, we have low concern that this has biased our results as $>90 \%$ of our patients consent to the PROs. Although the tobacco use questionnaire contains questions regarding number of cigarettes smoked per day and years a patient has smoked, there was $>60 \%$ missing data for these questions; thus we could not evaluate whether there was a dose-effect relationship between patient characteristics and pack-years of smoking. Some of our effect sizes are modest and thus may potentially be statistically significant without representing clinical significance. However we note that our findings on the associations of male gender, respiratory diseases, detectable HIV viral load, depression, anxiety, and substance abuse with smoking are consistent with prior studies among HIV-positive patients. Family history and heritability have been shown to play an important role in smoking, substance abuse, and mental illness, however we lacked data on family history [52-54]. However, we note our ability to control for a number of important sociodemographic, clinical, and behavioral factors available through our cohort database and PRO platform. Finally, one cross-sectional study from a single site has limited generalizability to other national or international settings.

\section{Conclusion}

Based on our findings, smoking cessation programs in HIV clinic settings may achieve greater impact by integrating interventions to address illicit substance use and mental illness into their protocols given the high co-occurrence of these conditions. Given the impact of smoking on morbidity and mortality among HIV-positive patients, and its attenuating effects on the benefits afforded by ART, the development and implementation of effective smoking cessation programs is a high priority in this population. 
Citation: Zyambo CM, Willig JH, Cropsey KL, Carson AP, Wilson C, et al. (2015) Factors Associated With Smoking Status among HIV-Positive Patients in Routine Clinical Care. J AIDS Clin Res 6: 480. doi:10.4172/2155-6113.1000480

\section{Acknowledgements}

Special thanks to Suneetha Thogaripolly, Anuj Kapil, and Mohit Varshney for the data retrieval. We thank the UAB 1917 Clinic Cohort staff and management for their assistance with this project.

\section{Financial Support}

This work was supported by the UAB Center for AIDS Research-NIH (P30AI27767) and CNICS-NIH (1R24AI067039-1)

\section{Potential Conflict of Interest}

Greer A. Burkholder has received research support from Bristol-Myers Squibb and is a consultant for Definicare, LLC and Amgen. James H. Willig has received research support from the Bristol-Myers Squibb, Pfizer, Tibotec Therapeutics, and Definicare, LLC, and has consulted for Bristol-Myers Squibb and Gilead Sciences. Andrew O. Westfall has consulted for Definicare, LLC.

\section{References}

1. Lewden C, May T, Rosenthal E, Burty C, Bonnet F, et al. (2008) Changes in causes of death among adults infected by HIV between 2000 and 2005 The "Mortalité 2000 and 2005" surveys (ANRS EN19 and Mortavic). J Acquir Immune Defic Syndr 48: 590-598.

2. Sabin CA (2013) Do people with HIV infection have a normal life expectancy in the era of combination antiretroviral therapy? BMC Med 11: 251.

3. Antiretroviral Therapy Cohort Collaboration (2008) Life expectancy of individuals on combination antiretroviral therapy in high-income countries: A collaborative analysis of 14 cohort studies. Lancet 372: 293-299.

4. Go AS, Mozaffarian D, Roger VL, Benjamin EJ, Berry JD, et al. (2014) Heart disease and stroke statistics--2014 update: A report from the American Heart Association. Circulation 129: e28-e292.

5. USDoHaH, Department of Health and Human Services (2014) The Health Consequences of Smoking-50 Years of Progress: A Report of the Surgeon General. Atlanta: U.S. Department of Health and Human Services, Centers for Disease Control and Prevention, National Center for Chronic Disease Prevention and Health Promotion, Office on Smoking and Health.

6. CDC: Centers for Disease Control and Prevention. Health, United States. Hyattsville (MD): Centers for Disease Control and Prevention, National Center for Health Statistics. [Accessed 2014 December 17]. 2014.

7. Centers for Disease Control and Prevention (CDC) (2008) Smoking-attributable mortality, years of potential life lost, and productivity losses--United States, 2000-2004. MMWR Morb Mortal Wkly Rep 57: 1226-1228.

8. CDC, US Department of Health and Human Services (2014) The health consequences of smoking- 50 years of progress: a report of the Surgeon General. Atlanta, GA.

9. Jamal A, Agaku IT, O'Connor E, King BA, Kenemer JB, et al. (2014) Current cigarette smoking among adults--United States, 2005-2013. MMWR Morb Mortal Wkly Rep 63: 1108-1112

10. Mdodo R, Frazier EL, Dube SR, Mattson CL, Sutton MY, et al. (2015) Cigarette smoking prevalence among adults with HIV compared with the general adult population in the United States: cross-sectional surveys. Ann Intern Med 162: 335-344.

11. Lifson AR, Neuhaus J, Arribas JR, van den Berg-Wolf M, Labriola AM, et al (2010) Smoking-related health risks among persons with HIV in the Strategies for Management of Antiretroviral Therapy clinical trial. Am J Public Health 100: 1896-1903.

12. Mamary EM, Bahrs D, Martinez S (2002) Cigarette smoking and the desire to quit among individuals living with HIV. AIDS Patient Care STDS 16: 39-42.

13. Tesoriero JM, Gieryic SM, Carrascal A, Lavigne HE (2010) Smoking among HIV positive New Yorkers: prevalence, frequency, and opportunities for cessation. AIDS Behav 14: 824-835.

14. Cockerham L, Scherzer R, Zolopa A, Rimland D, Lewis CE, et al. (2010) Association of HIV infection, demographic and cardiovascular risk factors with all-cause mortality in the recent HAART era. J Acquir Immune Defic Syndr 53: 102-106.

15. Crothers K, Goulet JL, Rodriguez-Barradas MC, Gibert CL, Oursler KA, et al. (2009) Impact of cigarette smoking on mortality in HIV-positive and HIVnegative veterans. AIDS Educ Prev 21: 40-53.
16. Crothers K, Griffith TA, McGinnis KA, Rodriguez-Barradas MC, Leaf DA, et al. (2005) The impact of cigarette smoking on mortality, quality of life, and comorbid illness among HIV-positive veterans. J Gen Intern Med 20: 1142-1145.

17. Calvo-Sánchez M, Perelló R, Pérez I, Mateo MG, Junyent M, et al. (2013) Differences between HIV-infected and uninfected adults in the contributions of smoking, diabetes and hypertension to acute coronary syndrome: Two parallel case-control studies. HIV Med 14: 40-48.

18. Crothers K, Butt AA, Gibert CL, Rodriguez-Barradas MC, Crystal S, et al. (2006) Increased COPD among HIV-positive compared to HIV - negative veterans. Chest 130: 1326-1333.

19. Sigel K, Wisnivesky J, Gordon K, Dubrow R, Justice A, et al. (2012) HIV as an independent risk factor for incident lung cancer. AIDS 26: 1017-1025.

20. Fuster M, Estrada V, Fernandez-Pinilla MC, Fuentes-Ferrer ME, Tellez MJ, et al. (2009) Smoking cessation in HIV patients: rate of success and associated factors. HIV Med 10: 614-619.

21. Burkhalter JE, Springer CM, Chhabra R, Ostroff JS, Rapkin BD (2005) Tobacco use and readiness to quit smoking in low-income HIV-infected persons. Nicotine Tob Res 7: 511-522.

22. Shirley DK, Kesari RK, Glesby MJ (2013) Factors associated with smoking in HIV-infected patients and potential barriers to cessation. AIDS Patient Care STDS 27: 604-612

23. Kozak MS, Mugavero MJ, Ye J, Aban I, Lawrence ST, et al. (2012) Patient reported outcomes in routine care: Advancing data capture for HIV cohort research. Clin Infect Dis 54: 141-147.

24. http://www.cdc.gov/tobacco/data_statistics/state_data/state_highlights/2010/ states/alabama/index.html

25. Reynolds NR (2009) Cigarette smoking and HIV: more evidence for action AIDS Educ Prev 21: 106-121.

26. Humfleet GL, Delucchi K, Kelley K, Hall SM, Dilley J, et al. (2009) Characteristics of HIV-positive cigarette smokers: A sample of smokers facing multiple challenges. AIDS Educ Prev 21: 54-64.

27. Lawrence D, Mitrou F, Zubrick SR (2009) Smoking and mental illness: results from population surveys in Australia and the United States. BMC Public Health 9: 285.

28. Webb MS, Vanable PA, Carey MP, Blair DC (2007) Cigarette smoking among $\mathrm{HIV}+$ men and women: Examining health, substance use, and psychosocial correlates across the smoking spectrum. J Behav Med 30: 371-383.

29. Bing EG, Burnam MA, Longshore D, Fleishman JA, Sherbourne CD, et al. (2001) Psychiatric disorders and drug use among human immunodeficiency virus-infected adults in the United States. Arch Gen Psychiatry 58: 721-728.

30. Galea S, Nandi A, Vlahov D (2004) The social epidemiology of substance use. Epidemiol Rev 26: 36-52.

31. Ho MK, Goldman D, Heinz A, Kaprio J, Kreek MJ, et al. (2010) Breaking barriers in the genomics and pharmacogenetics of drug addiction. Clin Pharmacol Ther 88: 779-791.

32. Zuckerman M, Kuhlman DM (2000) Personality and risk-taking: Common biosocial factors. J Pers 68: 999-1029.

33. Vollrath ME, Torgersen S (2008) Personality types and risky health behaviors in Norwegian students. Scand J Psychol 49: 287-292.

34. Dani JA, Jenson D, Broussard JI, De Biasi M (2011) Neurophysiology of Nicotine Addiction. J Addict Res Ther S1.

35. Hall SM, Prochaska JJ (2009) Treatment of smokers with co-occurring disorders: Emphasis on integration in mental health and addiction treatment settings. Annu Rev Clin Psychol 5: 409-431.

36. Feldman JG, Minkoff H, Schneider MF, Gange SJ, Cohen M, et al. (2006) Association of cigarette smoking with HIV prognosis among women in the HAART era: A report from the women's interagency HIV study. Am J Public Health 96: 1060-1065.

37. Mugavero MJ, Lin HY, Willig JH, Westfall AO, Ulett KB, et al. (2009) Missed visits and mortality among patients establishing initial outpatient HIV treatment. Clin Infect Dis 48: 248-256.

38. van Zyl-Smit RN, Brunet L, Pai M, Yew WW (2010) The convergence of the global smoking, COPD, tuberculosis, HIV, and respiratory infection epidemics. Infect Dis Clin North Am 24: 693-703. 
Citation: Zyambo CM, Willig JH, Cropsey KL, Carson AP, Wilson C, et al. (2015) Factors Associated With Smoking Status among HIV-Positive Patients in Routine Clinical Care. J AIDS Clin Res 6: 480. doi:10.4172/2155-6113.1000480

Page 7 of 7

39. Morris A, George MP, Crothers K, Huang L, Lucht L, et al. (2011) HIV and chronic obstructive pulmonary disease: Is it worse and why? Proc Am Thorac Soc 8: 320-325.

40. Gingo MR, Morris A, Crothers K (2013) Human immunodeficiency virusassociated obstructive lung diseases. Clin Chest Med 34: 273-282.

41. Diaz PT, King MA, Pacht ER, Wewers MD, Gadek JE, et al. (2000) Increased susceptibility to pulmonary emphysema among HIV-seropositive smokers. Ann Intern Med 132: 369-372.

42. Twardella D, Loew M, Rothenbacher D, Stegmaier C, Ziegler H, et al. (2006) The diagnosis of a smoking-related disease is a prominent trigger for smoking cessation in a retrospective cohort study. J Clin Epidemiol 59: 82-89.

43. Ives SP, Heuschmann PU, Wolfe CD, Redfern J (2008) Patterns of smoking cessation in the first 3 years after stroke: The South London Stroke Register. Eur J Cardiovasc Prev Rehabil 15: 329-335.

44. Houston TK, Scarinci IC, Person SD, Greene PG (2005) Patient smoking cessation advice by health care providers: The role of ethnicity, socioeconomic status, and health. Am J Public Health 95: 1056-1061.

45. Lopez-Quintero C, Crum RM, Neumark YD (2006) Racial/ethnic disparities in report of physician-provided smoking cessation advice: Analysis of the 2000 National Health Interview Survey. Am J Public Health 96: 2235-2239.

46. Stall RD, Greenwood GL, Acree M, Paul J, Coates TJ (1999) Cigarette smoking among gay and bisexual men. Am J Public Health 89: 1875-1878.

47. Tang H, Greenwood GL, Cowling DW, Lloyd JC, Roeseler AG, et al. (2004)
Cigarette smoking among lesbians, gays, and bisexuals: how serious a problem? (United States). Cancer causes and control 15: 797-803.

48. Deshpande PR, Rajan S, Sudeepthi BL, Abdul Nazir CP (2011) Patient-reported outcomes: A new era in clinical research. Perspect Clin Res 2: 137-144.

49. Kissinger P, Rice J, Farley T, Trim S, Jewitt K, et al. (1999) Application of computer-assisted interviews to sexual behavior research. Am J Epidemiol 149: 950-954.

50. Patrick DL, Cheadle A, Thompson DC, Diehr P, Koepsell T, et al. (1994) The validity of self-reported smoking: A review and meta-analysis. Am J Public Health 84: 1086-1093.

51. Hasley S (1995) A comparison of computer-based and personal interviews for the gynecologic history update. Obstet Gynecol 85: 494-498.

52. Tarnoki DL, Tarnoki AD1, Littvay L2, Lazar Z3, Karlinger K1, et al. (2014) Transmission of second-hand smoke sensitivity and smoking attitude in a family. Ann Agric Environ Med 21: 771-775.

53. Colamussi L, Bovbjerg DH, Erblich J (2007) Stress- and cue-induced cigarette craving: Effects of a family history of smoking. Drug Alcohol Depend 88: 251 258.

54. Kendler KS, Edwards A, Myers J, Cho SB, Adkins A, et al. (2015) The predictive power of family history measures of alcohol and drug problems and internalizing disorders in a college population. Am J Med Genet B Neuropsychiatr Genet 168: 337-346. 